\title{
The Association Between Prediabetes and Dyslipidemia Among Attendants of Primary Care Health Centers in Jeddah, Saudi Arabia
}

This article was published in the following Dove Press journal: Diabetes, Metabolic Syndrome and Obesity: Targets and Therapy

\author{
Turki Al Amri $\mathbb{D}^{1,2}$ \\ Suhad Bahijri (10) 2,3 \\ Rajaa Al-Raddadi (iD ${ }^{2,4}$ \\ Ghada Ajabnoor ${ }^{2,3}$ \\ Jawaher Al Ahmadi $\mathbb{D}^{2,4}$ \\ Hanan Jambi (iD) 2,5 \\ Anwar Borai ${ }^{2,6}$ \\ Jaakko Tuomilehto $2,7,8$ \\ 'Family and Community Medicine \\ Department, Faculty of Medicine-Rabigh \\ Branch, King Abdulaziz University, \\ Jeddah, Saudi Arabia; ${ }^{2}$ Saudi Diabetes \\ Study Research Group, King Fahd Medical \\ Research Center, King Abdulaziz \\ University, Jeddah, Saudi Arabia; \\ ${ }^{3}$ Department of Clinical Biochemistry, \\ Faculty of Medicine, King Abdulaziz \\ University, Jeddah, Saudi Arabia; \\ ${ }^{4}$ Department of Community Medicine, \\ Faculty of Medicine, King Abdulaziz \\ University, Jeddah, Saudi Arabia; \\ ${ }^{5}$ Department of Food and Nutrition, \\ Faculty of Home Economics, King \\ Abdulaziz University, Jeddah, Saudi \\ Arabia; ${ }^{6}$ King Abdullah International \\ Medical Research Center, King Saud Bin \\ Abdulaziz University for Health Sciences, \\ Pathology, King Abdulaziz Medical City, \\ Jeddah, Saudi Arabia; ${ }^{7}$ Center for \\ Vascular Prevention, Danube University \\ Krems, Krems, Austria; ${ }^{8}$ Public Health \\ Solutions, National Institute for Health \\ and Welfare, Helsinki, Finland
}

Introduction: Early detection and treatment of dysglycemia including diabetes and prediabetes is demonstrated to improve disease outcomes and prevent complications.

Objective: To assess the association of prediabetes with lipid metabolism disorders to clarify whether systematic screening for prediabetes should be proposed for individuals with dyslipidemia.

Material and Methods: A cross-sectional study design, employing a stratified two-stage cluster sampling method recruited non-diabetic adults (age $\geq 18$ years) from attendees of Primary Health Care (PHC) centers in Jeddah. Anthropomorphic measurements, demographic and clinical information were taken, and blood pressure was measured. Fasting blood sample was obtained for the measurement of plasma glucose (FPG), glycated hemoglobin (HbA1C), and lipid profile. Plasma glucose was estimated $1 \mathrm{hr}$ after the ingestion of $50 \mathrm{~g}$ glucose (1h-OGTT). Prediabetes and dyslipidemia were defined according to international guidelines. Demographic and clinical factors of subjects with prediabetes, and those with normoglycemia were compared. Multiple logistic regression analysis was used to adjust for confounding factors.

Results: A total of 613 individuals were included with a mean age $( \pm \mathrm{SD})$ of $32 \pm 11$.8years, and $54.8 \%$ being female. Prediabetes was detected in $28.7 \%$, and dyslipidemia in $54.2 \%$ of participants. After adjusting for age, an association was found for high low-density lipoproteincholesterol (LDL-C) and prediabetes based on any definition. After adjustment for body mass index (BMI), the association was retained for any type of dyslipidemia and in particular high LDL-C. After adjusting for both age and BMI, a significant association was found only between high LDL-C and prediabetes based on any definition (OR, 95\% $\mathrm{CI}=1.50,1.02-2.19, \mathrm{P}=0.037$ ). Conclusion: Even though high LDL-C is associated with an increased probability of prediabetes, a recommendation for universal screening of dyslipidemic patients requires further cohort studies.

Key words: prediabetes, dyslipidemia, Saudi, normoglycemia, screening, OGTT

\section{Introduction}

Prediabetes is defined as a non-diabetic level of hyperglycemia, which is indicated by either impaired fasting glucose (IFG), impaired glucose tolerance (IGT), or glycated hemoglobin (HbA1c) level between 5.7 and $6.4^{1,2}$ It constitutes a premorbid state with an increased risk of progression to type 2 diabetes (T2DM), with which it shares the same pathophysiological process of insulin resistance and/or defect in insulin secretion. ${ }^{3-5}$ Individuals with prediabetes are at a greater risk of developing microvascular complications including retinopathy, nephropathy and
Correspondence: Rajaa Al-Raddadi Department of Community Medicine, Faculty of Medicine, King Abdulaziz University, Jeddah, Saudi Arabia Tel +96650559138I

Email saudiresearcher@yahoo.com 
neuropathy compared to those with normal blood glucose levels. $^{6-9}$ Prediabetes is also associated with an increased risk of cardiovascular disease. ${ }^{1,2}$

The detection of individuals with prediabetes enables early management to prevent or at least delay the onset of frank diabetes ${ }^{10-12}$. Prediabetes is believed to be underdiagnosed among Saudis due to the lack of the national screening program and inadequate detection methodology, which is mostly based on fasting blood assessment; however, only a fraction of people with prediabetes will have IFG.

Insulin resistance, known to be a strong predictor of prediabetes, is reported to be associated with visceral obesity, hypertension, glucose intolerance, dyslipidemia, endothelial dysfunction, atherosclerotic, and hyperinsulinemia. ${ }^{13}$ In addition to genetic susceptibility and unhealthy lifestyle, prediabetes has been reported to be associated with several sociodemographic and clinical factors such as age, abdominal obesity, hypertriglyceridemia, and low education levels. $^{14-16}$ The American blood cholesterol guideline recommends the assessment of glycaemia status in people with hyperlipidemia who have no atherosclerotic vascular disease and are not treated with statins. ${ }^{17}$ High-intensity statin therapy is preferentially recommended for individuals aged 40 to 75 years with diabetes and a $\geq 7.5 \%$ estimated 10 year atherosclerotic cardiovascular disease (ASCVD) risk since diabetes markedly increases lifetime risk for ASCVD events and death. However, they did not make any recommendation regarding prediabetes.

\section{Objectives}

In this study we aimed at assessing the association of prediabetes with lipid metabolism disorders, taking into account the influence of other demographic and clinical factors found to be of significance in the earlier survey. ${ }^{14}$ With this, we hoped to investigate whether screening for prediabetes should be proposed for individuals with dyslipidemia. Also, we aimed at determining the parameter(s) with the strongest association with prediabetes in order to help to design appropriate diabetes prevention programs for the local population.

\section{Materials and Methods Design and Setting}

A cross-sectional study design recruited non-diabetic adults (age $\geq 18$ years) from attendees of Primary Health Care (PHC) centers in Jeddah, Saudi Arabia. The study was approved by the Department of Medical Research and
Studies, Directorate of Health Affairs, Jeddah, Ministry of Health, as well as the Committee on the Ethics of Human Research at the Faculty of Medicine - King Abdulaziz University. This study was conducted in accordance with the Declaration of Helsinki.

A stratified two-stage cluster sampling method was used for the inclusion of participants. ${ }^{18}$ At the first stage, one PHC center out of each of the five geographical sectors in Jeddah was selected using a simple random selection method in order to cover all socioeconomic classes. At the second stage, eligible people were included using systematic sampling, until reaching the target sample size, which was calculated based on previous studies in Jeddah. $^{14,19}$

Within each cluster, the target sample size was calculated, taking into account the population density, to detect the association between prediabetes and dyslipidemia with 95\% confidence interval and 0.05 precision. Thus, the actual calculated sample size using "Open epi program" was 578 according to previously published study which was conducted in the same location ${ }^{19}$ but at least 670 people were aimed for to ensure adequate gender representation, and to cover for missing data and/or the presence of undiagnosed diabetes.

People aged $<18$ years, pregnant women, noncommunicant or mentally disabled people were excluded. The study objectives and procedure were explained to all people and a written consent was obtained from the consenting ones prior to inclusion.

\section{Study Procedure and Data Collection}

All people consenting were given an appointment to come to the clinic after fasting for at least $12 \mathrm{hrs}$. On the visit, the participants were interviewed individually to complete a pre-designed, structured questionnaire that included sociodemographic data (age, sex, educational level, ethnic background, number of children, monthly income, and profession), as well as family and personal medical history.

Anthropomorphic measurements including height, weight, and waist circumference (WC) were taken, and blood pressure (BP) was measured. A stadiometer was used to measure the height barefooted to the closest $0.5 \mathrm{~cm}$, and a calibrated scale (Omron BF511) was used to measure the weight to the nearest $0.5 \mathrm{~kg}$, while wearing light street clothing. Measured height and weight were used to calculate body mass index (BMI). Blood pressure was measured using an electronic 
sphygmomanometer (KBM Mercurial Desk type SM300). Two BP readings were taken within a gap of 1 min, after the person has been seated for 10 mins, and the mean of the two readings was calculated. A third measurement was taken and the mean of the two closest values was calculated if there was a difference $>5 \mathrm{mmHg}$ between the two first measures. Hypertension was defined as systolic BP $\geq 140 \mathrm{mmHg}$ and/or diastolic BP $\geq 90 \mathrm{mmHg}$, or current use of antihypertensive medication. $^{20}$

A fasting blood sample was obtained for the measurement of plasma glucose level, glycated hemoglobin (HbA1c), and the lipid profile including serum total cholesterol (TC), high-density lipoprotein-cholesterol (HDL-C) and triglycerides (TG) levels. A $1 \mathrm{hr}$ oral glucose tolerance test (1h-OGTT) was then performed by giving the participant a $50 \mathrm{~g}$ oral glucose drink (CASCO NERL Diagnostics, East Providence, RI, USA), and taking a second blood sample for $1 \mathrm{hr}$ plasma glucose (1-hPG) estimation. ${ }^{21}$ We decided to use $50 \mathrm{~g}$ glucose load because it was found that $50 \mathrm{~g}$ and $75 \mathrm{~g}$ load produced similar 1-hPG levels in non-diabetic individuals. ${ }^{22}$

\section{Biochemical Assays}

HbA1c was measured with high-pressure liquid chromatography (HPLC) using automated HbA1c analyzer G8 (TOSOH Bioscience, Inc). Plasma glucose, and serum TC, HDL-C and TG levels were measured by spectrophotometric methods using ABBOTT, Architect c8000 auto-analyzer. Low-density lipoprotein- cholesterol (LDL-C) was calculated using the Friedewald equation. ${ }^{23}$

\section{Diagnosing Dyslipidemia and Prediabetes}

Prediabetes was defined as HbA1c 5.7-6.4\% (39-46 mmol/ $\mathrm{mol})$, impaired fasting glucose (IFG) $(\mathrm{FPG}=6.1-6.9 \mathrm{mmol} / \mathrm{L})$, and impaired glucose tolerance (IGT) (1h-OGTT=7.8-11.0 $\mathrm{mmol} / \mathrm{L}) .{ }^{21}$ Participants with $\mathrm{HbA} 1 \mathrm{c} \geq 6.5 \%, \mathrm{FPG} \geq 7 \mathrm{mmol} /$ L or $1 \mathrm{~h}-\mathrm{OGTT} \geq 11.1 \mathrm{mmol} / \mathrm{L}$ were considered as diabetic and were excluded from the study. ${ }^{21,24,25}$ Dyslipidemia was defined as LDL-C $\geqslant 3.37 \mathrm{mmol} / \mathrm{L}$, HDL-C $<1.04 \mathrm{mmol} / \mathrm{L}$ for men and $<1.3 \mathrm{mmol} / \mathrm{L}$ for women, total cholesterol $\geqslant 5.18$ $\mathrm{mmol} / \mathrm{L}$, triglycerides $\geqslant 1.7 \mathrm{mmol} / \mathrm{L}$ or treatment with lipidlowering drugs with all lipid levels in the normal range. ${ }^{26,27}$

\section{Statistical Methods}

Statistical analysis was carried out using SPSS, version 21. Descriptive statistics were calculated for all measured and estimated parameters and were presented as mean \pm standard deviation (SD) for continuous variables, and as frequency (percentages) for categorical variables. Demographic, lifestyle and clinical factors of prediabetes were analyzed by comparing participants who were identified to have prediabetes and those with normoglycemia. Factors with continuous variables were analyzed using an independent $t$-test, while those with categorical variables were analyzed using Chi-square test or Fisher's exact test, as appropriate.

Multiple logistic regression analysis was used to adjust for confounding factors. Unadjusted and adjusted Odds Ratio (OR) with its 95\% Confidence Interval (CI) for the predictors of prediabetes were presented. Diagnosis of dyslipidemia using each or all lipid variables was included in the model as independent variables. Associations between each of the prediabetes parameters (HbAlc, FPG, and 1h-OGTT) and each of the dyslipidemia parameters (TC, TG, LDL, and HDL) were further analyzed. Statistical significance was assigned at $\mathrm{p}<0.05$.

\section{Results}

\section{Population Characteristics}

A total of 679 individuals were recruited; however, 66 (9.7\%) were excluded due to either absence of outcome measures (FPG, 1h-PG, and HbA1c) or being classified as diabetic following blood analysis. The mean age $( \pm \mathrm{SD})$ of the 613 included participants was $32 \pm 11.8$ years, with $55 \%$ being female. The majority descended from Arabian tribes (78\%), were non-smokers $(72 \%)$, reported recommended duration of physical activity (69\%), with $52 \%$ having at least basic university degrees, and $28 \%$ earning a low income of $\leq 5000$ SAR (1333 US\$)/month (Table 1).

Prediabetes by using any of the stated definitions was detected in 176 individuals (28.7\%), 29\% in men and 28\% in women. Only a small percentage (4.0\% of the total) were detected as subjects with prediabetes using FPG, while almost all $(81.8 \%$ were detected by the 1 h-OGTT, and $27.8 \%$ ) were detected by HbA1c. Measures of glycemic parameters used to identify prediabetes, as well as demographic, and anthropometric characteristics of subjects with prediabetes and normoglycemic participants are presented in Table 2.

Mean age and BMI were significantly higher and a higher percentage of people with no university degree, and with a very low income in the prediabetic group, but no significant difference was found in the percentage of smoking status, or ethnicity (not shown).

Clinical characteristics and lipid profile of people with prediabetes and normal glycemia are presented in Table 3. 
Table I Sociodemographic Characteristics of Studied Participants $(\mathrm{N}=613)$

\begin{tabular}{|c|c|c|}
\hline Parameter & Category & Percentage \\
\hline Sex & $\begin{array}{l}\text { Male } \\
\text { Female }\end{array}$ & $\begin{array}{l}45.2 \% \\
54.8 \%\end{array}$ \\
\hline Marital Status & $\begin{array}{l}\text { Not Married } \\
\text { Married }\end{array}$ & $\begin{array}{l}48.6 \% \\
51.4 \%\end{array}$ \\
\hline Educational attainment & $\begin{array}{l}\text { SPrimary school } \\
\text { Intermediate school } \\
\text { Secondary school } \\
\text { Diploma } \\
\text { Basic university degree } \\
\text { Post graduate degree }\end{array}$ & $\begin{array}{l}9.3 \% \\
6.4 \% \\
27.1 \% \\
5.4 \% \\
48.4 \% \\
3.6 \%\end{array}$ \\
\hline Ethnicity & $\begin{array}{l}\text { Arabian tribes } \\
\text { African tribes } \\
\text { Mediterranean } \\
\text { Indian continent } \\
\text { Middle Asia } \\
\text { South-Eastern Asia } \\
\text { Mixed race }\end{array}$ & $\begin{array}{l}77.5 \% \\
5.5 \% \\
3.3 \% \\
4.4 \% \\
2.0 \% \\
3.1 \% \\
4.2 \%\end{array}$ \\
\hline Monthly income (SAR) & $\begin{array}{l}\leq 5000 \\
>5000-10,000 \\
>10,000-20,000 \\
>20,000\end{array}$ & $\begin{array}{l}27.9 \% \\
24.8 \% \\
27.1 \% \\
20.2 \%\end{array}$ \\
\hline Smoking status: & $\begin{array}{l}\text { Non smoker } \\
\text { Smoker } \\
\text { Passive smoker } \\
\text { Former smoker }\end{array}$ & $\begin{array}{l}71.8 \% \\
16.2 \% \\
9.1 \% \\
2.9 \%\end{array}$ \\
\hline $\begin{array}{l}\text { Physical activity: (moderate } \\
\text { intensity) }\end{array}$ & $\begin{array}{l}<60 \mathrm{mins} / \text { week } \\
60-<150 \mathrm{mins} / \text { week } \\
\geq 150 \mathrm{mins} / \text { week }\end{array}$ & $\begin{array}{l}30.0 \% \\
1.0 \% \\
69.0 \%\end{array}$ \\
\hline
\end{tabular}

Establishing the categories of patients with high levels of total cholesterol, triglycerides, LDL, and low HDL took into account lipid-lowering therapy.

The means of SBP and the lipid parameters, except for HDL-C, and the percentage of people with high values were significantly higher in the prediabetic groups. Family history of diabetes and dyslipidemia did not differ between the two groups.

The association between prediabetes and dyslipidemia before and after adjusting for age and BMI are presented in Table 4.

Before adjustment, any type of dyslipidemia, alone or in any combination, and in particular high LDL-C, and triglycerides, was associated with increased probability of prediabetes identified by any definition, as well as for prediabetes based on HbAlc. In addition, high triglycerides were associated with increased probability of prediabetes identified by fasting blood glucose, and high LDL-C was associated with increased probability of prediabetes identified by $1 \mathrm{hr}$ post-load glucose level. After adjusting for age, the association was retained for high LDL-C and prediabetes based on any definition. After adjustment for BMI, the association was retained for any type of dyslipidemia and in particular high LDL-C, and prediabetes based on any definition, as well as for high triglycerides and prediabetes identified by FPG, and high LDL-C and prediabetes based on $1 \mathrm{hr}$ post-load glucose level. After adjusting for both age and BMI, only high LDL-C was found to be highly associated with increased probability of prediabetes based on any definition.

\section{Discussion and Conclusion}

Although there are several risk factors for impaired glucose metabolism, the present study focused on the significance of dyslipidemia as a predictor for prediabetes by assessing the association between prediabetes and lipid parameters, analyzing the strength of association of different parameters, and taking into account the potential influence or confounding effect of other demographic and clinical factors found to be of significance in an earlier survey carried out in Jeddah. ${ }^{14}$ To our knowledge, this is the first study in the Saudi population.

Using any of the three classification criteria IFG, IGT and high $\mathrm{HbA1c}(5.7-6.4 \%)$, prediabetes was detected in $28.7 \%$ of the participants, which is much higher than the $11.9 \%$ prevalence reported previously in Jeddah, ${ }^{14}$ but closer to an earlier national, household, population-based study of $22.6 \%{ }^{28}$ The noted differences in prevalence estimates might be attributed to the different methods used for defining prediabetes, as well as the difference in age between the populations studied, since age is one of the strongest predictors of diabetes and prediabetes in various populations, ${ }^{29-31}$ including our own. ${ }^{14}$ Prediabetes was identified in only 7 individuals (or $4.0 \%$ of total people with prediabetes) using FPG, confirming the earlier suggestion of low sensitivity of FPG to detect diabetes and prediabetes. Indeed, it appears that the use of an OGTT, which has been promoted by $\mathrm{WHO}^{32}$ is still the most suitable method for detecting diabetes and prediabetes. However, the traditional OGTT is inconvenient to use in surveys due to the length of time needed. Instead, we used the 1h-OGTT, proven in an earlier study to be accurate and sensitive in identifying prediabetes in screening. ${ }^{21}$ Prediabetes was detected in most cases 
Table 2 Comparison of Measures of Glycemic Parameters, Demographic, and Anthropometric Characteristics Between Prediabetic and Normoglycemic Individuals

\begin{tabular}{|c|c|c|c|}
\hline & Normoglycemia (N=437) & Prediabetes $(\mathrm{N}=176)$ & P-value \\
\hline FPG $(\mathrm{mmol} / \mathrm{L})($ mean $\pm S \mathrm{D})$ & $4.21 \pm 0.46$ & $4.62 \pm 0.64$ & $<0.001 *$ \\
\hline I hr Glucose (mmol/L) (mean \pm SD) & $5.82 \pm 1.15$ & $8.48 \pm 1.19$ & $<0.001 *$ \\
\hline HbAlc (\%) (mean \pm SD) & $5.09 \pm 0.33$ & $5.38 \pm 0.41$ & $<0.001 *$ \\
\hline Age (years) (mean $\pm S D$ ) & $29.68 \pm 10.43$ & $37.27 \pm 13.07$ & $<0.001 *$ \\
\hline \multicolumn{4}{|l|}{$\operatorname{Sex}(N=6 \mid 3)$} \\
\hline Male (N=277, \%) & $70.8 \%$ & $29.2 \%$ & 0.792 \\
\hline Female $(\mathrm{N}=336, \%)$ & $71.7 \%$ & $28.3 \%$ & \\
\hline BMl kg/m² (mean $\pm S D)$ & $26.68 \pm 6.03$ & $29.25 \pm 6.09$ & $<0.00 I^{*}$ \\
\hline \multicolumn{4}{|l|}{ Smoking status $(\mathrm{N}=6 \mid 3)$} \\
\hline Non smoker $(N=440)$ & $71.4 \%$ & $72.7 \%$ & \\
\hline Smoker $(\mathrm{N}=99)$ & $15.8 \%$ & $17.0 \%$ & 0.617 \\
\hline Passive Smoker $(\mathrm{N}=56)$ & $10.1 \%$ & $6.8 \%$ & \\
\hline Former smoker $(\mathrm{N}=\mid 8)$ & $2.7 \%$ & $3.4 \%$ & \\
\hline \multicolumn{4}{|l|}{ Educational attainment $(\mathrm{N}=6 \mid 3)$} \\
\hline$\leq$ Primary school $(\mathrm{N}=57)$ & $5.9 \%$ & $17.6 \%$ & \\
\hline Intermediate school ( $\mathrm{N}=39)$ & $5.3 \%$ & $9.1 \%$ & $<0.001 *$ \\
\hline Secondary school and Diploma (N=199) & $33.0 \%$ & $31.1 \%$ & \\
\hline Basic and post graduate university degree $(N=3 \mid 8)$ & $55.8 \%$ & $42.0 \%$ & \\
\hline \multicolumn{4}{|l|}{ Monthly income (SAR) $(\mathrm{N}=6 \mid 3)$} \\
\hline$\leq 5000(N=|7|)$ & $24.9 \%$ & $35.2 \%$ & $<0.001 *$ \\
\hline$>5000-10,000(\mathrm{~N}=152)$ & $23.3 \%$ & $28.4 \%$ & \\
\hline$>10,000-20,000(\mathrm{~N} 167)$ & $27.2 \%$ & $26.7 \%$ & \\
\hline$>20,000(N=123)$ & $24.5 \%$ & $9.7 \%$ & \\
\hline
\end{tabular}

Note: *Statistically significant result ( $p$-value<0.05).

Abbreviations: FPG, Fasting plasma glucose; HbAlc, glycated hemoglobin.

$(81.8 \%)$ by this method in our study, giving further proof to its suitability as a method of choice for screening.

As expected it was found that means of age and BMI were significantly higher in the prediabetes group. In a cohort study on incident prediabetes and glycemic progression among black and white offspring of parents with T2DM, it was reported that older age and higher BMI at baseline were the most significant predictors of progression from normoglycemia to prediabetes. ${ }^{33}$

Therefore, they were adjusted for when performing regression analysis to find the best predictors of prediabetes. After adjustment, only high LDL-C was found to be highly associated with increased probability of prediabetes based on any definition.

Many previous studies ${ }^{34-36}$ investigated the association of dyslipidemia and prediabetes, and the presence of dyslipidemia has been reported to be associated with increased risk of progression of prediabetes to full type 2 diabetes
(T2DM), ${ }^{37,38}$ as well as rapid development and advanced stages of diabetic complications. ${ }^{35,39,40}$

In our study, a statistically significant association of prediabetes with all lipid parameters was noted in univariate analyses, similar to what was reported earlier in other populations, ${ }^{34,36}$ but neither of these studies performed regression analysis. In our study, before adjustment for age and BMI, it was found that any type of dyslipidemia, alone or in any combination, and in particular high LDL$\mathrm{C}$, and triglycerides were associated with increased probability of prediabetes identified by any definition, as well as for prediabetes based on HbAlc. However, after performing multiple logistic regression analysis, and adjusting for age and BMI, only high LDL-C remained significantly associated with increased risk of prediabetes using any definition. These results indicate the influence of age and BMI on dyslipidemia in our population, with age showing stronger effect than BMI. Our findings are in 
Table 3 Comparison of Clinical Characteristics, Lipid Profile and Family History Between People with Prediabetes and Normoglycemia

\begin{tabular}{|c|c|c|c|}
\hline & $\begin{array}{l}\text { Normoglycemia } \\
(\mathrm{N}=437)\end{array}$ & $\begin{array}{l}\text { Prediabetes } \\
(\mathbf{N}=176)\end{array}$ & P-value \\
\hline $\mathrm{SBP}($ mean $\pm \mathrm{SD})$ & $113.5 \pm 16.72$ & $117.13 \pm 16.19$ & $0.014 *$ \\
\hline People (\%) with high value( $\geq 140 \mathrm{mmHg}$ ) & $22(5.1 \%)$ & $13(7.4 \%)$ & 0.256 \\
\hline $\mathrm{DBP}($ mean $\pm \mathrm{SD})$ & $69.4| \pm| 2.7 \mid$ & $71.43 \pm 12.82$ & 0.076 \\
\hline People (\%) with high value (> $90 \mathrm{mmHg}$ ) & $35(8.1 \%)$ & $16(9.1 \%)$ & 0.384 \\
\hline $\begin{array}{l}\text { People (\%) with hypertension (SBP } \geq 140 \mathrm{mmHg} \text { and/or D BP }>90 \mathrm{mmHg} \text {, or current use } \\
\text { of antihypertensive medication) }\end{array}$ & $58(\mid 3.4 \%)$ & $29(16.5 \%)$ & 0.304 \\
\hline Total serum cholesterol (mean $\pm \mathrm{SD})$ & $4.67 \pm 0.95$ & $5.03 \pm 0.98$ & $<0.00 I^{*}$ \\
\hline No. of people $(\%)$ with high value $(\geqslant 5.18 \mathrm{mmol} / \mathrm{L})$ & $60(13.7 \%)$ & $37(21.0 \%)$ & $0.026^{*}$ \\
\hline Triglycerides (mean $\pm \mathrm{SD}$ ) & $1.08 \pm 0.56$ & $1.31 \pm 0.65$ & $<0.001 *$ \\
\hline No. of people (\%) with high value ( $\geqslant 1.7 \mathrm{mmol} / \mathrm{L})$ & $64(\mid 4.6 \%)$ & $38(21.6 \%)$ & $0.038^{*}$ \\
\hline $\mathrm{HDL}-\mathrm{C}($ mean $\pm \mathrm{SD})$ & $1.37 \pm 0.28$ & $1.35 \pm 0.27$ & 0.536 \\
\hline No. of people (\%) with low value (< $1.04 \mathrm{mmol} / \mathrm{L}$ for men and $<1.3 \mathrm{mmol} / \mathrm{L}$ for women) & $96(22.0 \%)$ & $46(26.1 \%)$ & 0.215 \\
\hline LDL -C (mean $\pm S D)$ & $3.08 \pm 0.85$ & $3.41 \pm 0.89$ & $<0.00 I^{*}$ \\
\hline No. of people (\%) with high value ( $\geqslant 3.37 \mathrm{mmol} / \mathrm{L})$ & $140(32.0 \%)$ & $85(48.3 \%)$ & $<0.00 I^{*}$ \\
\hline No. of subjects (\%) with dyslipidemia & $217(49.7 \%)$ & $115(65.3 \%)$ & $<0.00 I^{*}$ \\
\hline Non-HDL cholesterol (mean \pm SD) & $3.30 \pm 0.92$ & $3.67 \pm 0.94$ & $<0.00 I^{*}$ \\
\hline LDL -C: HDL -C (mean \pm SD) & $2.34 \pm 0.81$ & $2.61 \pm 0.80$ & $<0.00 I^{*}$ \\
\hline Family history of dyslipidemia & $219(50.1 \%)$ & 79 (44.9\%) & $0.24 I$ \\
\hline Family history of diabetes & $303(69.3 \%)$ & $129(73.3 \%)$ & 0.331 \\
\hline
\end{tabular}

Notes: Dyslipidemia was defined as LDL-C $\geqslant 3.37 \mathrm{mmol} / \mathrm{L}$, HDL-C $<1.04 \mathrm{mmol} / \mathrm{L}$ for men and $<1.3 \mathrm{mmol} / \mathrm{L}$ for women, total cholesterol $\geqslant 5.18 \mathrm{mmol} / \mathrm{L}$, triglycerides $\geqslant$ $1.7 \mathrm{mmol} / \mathrm{L}$ or treatment with lipid-lowering drugs. *Statistically significant result $(\mathrm{p}$-value $<0.05)$.

Abbreviations: SBP, systolic blood pressure; DBP, diastolic blood pressure; HDL -C, high-density lipoprotein-cholesterol; LDL -C, low-density lipoprotein-cholesterol.

partial accordance with earlier findings in a cohort study conducted in Memphis, USA on white and black offspring of parents with T2DM, to investigate whether individual lipid moieties at baseline had congruent relationships with glycemia, and adiposity as well as insulin sensitivity and insulin secretion. ${ }^{37}$ In this American study higher baseline plasma levels of cholesterol, LDL-C, and triglycerides significantly increased the risk of incident prediabetes/ T2DM, indicating that dyslipidemia preceded dysglycemia. Therefore, it was concluded that among healthy offspring of parents with T2DM, baseline lipid profiles predicted incident prediabetes/T2DM. They also reported that higher baseline levels of HDL-C significantly decreased the risk of incident prediabetes/T2DM, in contrast to our findings of no association between HDL-C level and risk of prediabetes. In spite of the fact that our study used cross-sectional design, similar conclusions can be made from our results, which are in keeping with the Memphis study, in that people with high LDL-C are at higher risk of prediabetes. Even though not all people with prediabetes will develop diabetes during a short follow-up, those with dyslipidemia were most likely and rapidly to develop diabetes, and also subsequent cardiovascular disease (CVD). ${ }^{41,42}$ Serum lipid levels are commonly determined as a part of CVD prevention activities based on current guidelines on diabetes and prediabetes. ${ }^{43}$ However, a thorough investigation of dysglycemia is not commonly requested, and only fasting glucose is estimated, causing it to be under-diagnosed, and increasing the future risk of both diabetes and CVD. 
Table 4 Adjusted and Unadjusted Odds Ratio (OR) for Dyslipidemia Covariates Associated with Prediabetes Using Different Definitions Presented as or $(95 \% \mathrm{Cl})$

\begin{tabular}{|c|c|c|c|c|}
\hline Covariate & $\begin{array}{l}\text { Prediabetes (Any } \\
\text { Definition) Total }(\mathrm{N}=\mid \mathrm{I6}) \\
\text { OR }(95 \% \mathrm{Cl})\end{array}$ & $\begin{array}{l}\text { FBG }(6.1-6.9 \mathrm{mmol} / \mathrm{L}) \\
(\mathrm{N}=7) \\
\text { OR }(95 \% \mathrm{Cl})\end{array}$ & $\begin{array}{l}\text { Glucose I hr (7.8-I I.I } \\
\mathrm{mmol} / \mathrm{L})(\mathrm{N}=\mid 44) \\
\text { OR }(95 \% \mathrm{Cl})\end{array}$ & $\begin{array}{l}\text { HbAlc }(5.7-6.4 \%) \\
(\mathrm{N}=49) \\
\text { OR }(95 \% \mathrm{Cl})\end{array}$ \\
\hline \multicolumn{5}{|l|}{ Any type of Dyslipidemia } \\
\hline Unadjusted OR (95\% Cl) & $1.91(1.33-2.75), 0.000^{*}$ & $2.12(0.4 I-10.9), 0.372$ & $1.70(1.15-2.5 \mathrm{I}), 0.008^{*}$ & 2.52 (I.3I-4.84), 0.006* \\
\hline Adjusted for age & $1.45(0.99-2.13), 0.058^{*}$ & I.3। (0.24-7.I3), 0.752 & $1.29(0.85-1.95), 0.226$ & 1.77 (0.89-3.49), 0.103 \\
\hline Adjusted for BMI & $1.62(1.12-2.37), 0.01 I^{*}$ & I.77 (0.33-9.45), 0.505 & 1.48 (0.99-2.22), 0.056 & 1.96 (I.00-3.83), $0.05 \mathrm{I}$ \\
\hline Adjusted for age and BMI & $1.38(0.94-2.04), 0.102$ & I.3। (0.24-7.|4), 0.752 & 1.25 (0.82-1.89), $0.30 \mathrm{I}$ & $1.66(0.83-3.27), 0.152$ \\
\hline \multicolumn{5}{|l|}{ High TC } \\
\hline Unadjusted OR (95\% Cl) & $1.66(1.06-2.62), 0.028^{*}$ & $2.14(1.05-11.17), 0.369$ & $1.42(0.87-2.30), 0.162$ & $1.82(0.91-3.62), 0.090$ \\
\hline Adjusted for age & I.I3(0.70-I.84), 0.626 & I. $19(0.22-6.46), 0.840$ & 0.96 (0.57-I.62), 0.890 & I.II (0.54-2.32), 0.769 \\
\hline Adjusted for BMI & $1.46(0.92-2.32), 0.112$ & $1.86(0.35-9.88), 0.466$ & 1.27 (0.78-2.08), 0.343 & 1.50 (0.74-3.04), 0.263 \\
\hline Adjusted for age and BMI & $1.09(0.67-1.78), 0.717$ & 1.19 (0.22-6.47), 0.839 & $0.96(0.57-1.61), 0.866$ & 1.09 (0.52-2.27), 0.817 \\
\hline \multicolumn{5}{|l|}{ High TG } \\
\hline Unadjusted OR (95\% Cl) & I.60(I.02-2.49), 0.040* & $6.86(I .5 I-3 \mid . I), 0.013^{*}$ & $1.45(0.90-2.35), 0.131$ & $2.15(1.11-4.16), 0.023 *$ \\
\hline Adjusted for age & $1.04(0.64-1.68), 0.88 \mathrm{I}$ & 3.78 (0.89-17.8), 0.093 & 0.99 (0.59-I.65), 0.961 & 1.30 (0.65-2.62), 0.463 \\
\hline Adjusted for BMI & $1.05(0.65-1.70), 0.843$ & $5.97(1.24-28.8), 0.026^{*}$ & $1.19(0.72-1.96), 0.501$ & $1.54(0.77-3.06), 0.222$ \\
\hline Adjusted for age and BMI & $0.97(0.60-1.58), 0.909$ & 3.77 (0.79-17.9), 0.095 & $0.94(0.56-1.57), 0.805$ & I.I8 (0.58-2.38), 0.645 \\
\hline \multicolumn{5}{|l|}{ High LDL-C } \\
\hline Unadjusted OR (95\% Cl) & $1.99(1.39-2.85), 0.000 *$ & 1.29 (0.29-8.83), 0.738 & 1.72 (1.17-2.53), 0.006* & 2.09 (1.16-3.76), $0.014^{*}$ \\
\hline Adjusted for age & $1.56(1.06-2.27), 0.022^{*}$ & 0.87 (I.87-4.08), 0.864 & 1.33 (0.89-1.99), 0.168 & I.5। (0.82-2.79), 0.191 \\
\hline Adjusted for BMI & $1.75(1.21-2.52), 0.003^{*}$ & 1.29 (0.28-5.83), 0.738 & 1.55 (1.04-2.29), 0.030* & 1.69 (0.93-3.09), 0.088 \\
\hline Adjusted for age and BMI & $1.50(1.02-2.19), 0.037^{*}$ & $0.88(0.19-4.12), 0.866$ & 1.30 (0.86-I.95), 0.211 & $\mathrm{I} .40(0.75-2.6 \mathrm{I}), 0.286$ \\
\hline \multicolumn{5}{|l|}{ Low HDL-C } \\
\hline Unadjusted OR (95\% Cl) & $1.22(0.86-1.93), 0.221$ & $4.44(0.98-20.1), 0.053$ & $1.01(0.65-1.57), 0.963$ & $2.23(1.22-4.10), 0.010$ \\
\hline Adjusted for age & 0.94 (0.6I-I.45), 0.779 & $2.53(0.53-12.1), 0.244$ & 0.75 (0.47-1.20), 0.227 & $1.53(0.80-2.91), 0.199$ \\
\hline Adjusted for BMI & I.I 4 (0.75-I.72), 0.539 & 4.02 (0.88-18.3), 0.072 & $0.90(0.57-I .4 I), 0.634$ & 1.95 (1.05-3.63), 0.053 \\
\hline Adjusted for age and BMI & $0.91(0.59-1.40), 0.667$ & 2.51 (0.53-II.9), 0.249 & 0.73 (0.46-I.I7), 0.197 & $\mathrm{I} .54$ (0.8I-2.93), 0.193 \\
\hline
\end{tabular}

Note: *Statistically significant result ( $\mathrm{p}$-value $<0.05)$.

In conclusion, our study showed that there is a high prevalence of prediabetes among attendees of PHC in Jeddah reaching $29 \%$, with IGT accounting for the majority of the detected cases. Dyslipidemia was present in 54\% of the total population, with high LDL-C in particular being associated with an increased probability of prediabetes after adjusting for age and BMI.

Our study has points of strengths as well as limitations.

The main strength of this study is that it is the first indepth study in the Saudi population using different definitions of prediabetes and the commonly used components of the lipid profile.
The major limitation is a common limitation to all similar cross-sectional studies in that an association can be only suggested, but a cohort study is needed to verify any made suggestions. Therefore, based on our results, recommendation for universal screening of all dyslipidemic patients would require further cohort studies to determine the downstream effects of screening.

Early detection of prediabetes will help to initiate dietary and lifestyle strategies, or even pharmacotherapy as appropriate, in order to prevent or delay the progression to overt T2DM, ${ }^{44}$ and thereby delay its associated increased risk of CVD. ${ }^{1,2}$ Keeping in mind the high prevalence of T2DM in 
the Saudi population, there is an urgent need for effective prediabetes screening and prevention programs that should be designed, taking into account the identified predictors, as well as screening for prediabetes among dyslipidemic patients vs screening among other at-risk populations.

\section{Abbreviations}

IFG, impaired fasting glucose, IGT, impaired glucose tolerance, T2DM, type 2 diabetes mellitus, HBA1c, glycosylated hemoglobin, ASCVD, atherosclerotic cardiovascular disease, PHC, primary health care, WC, waist circumference, BP, blood pressure, BMI, body mass index, TC, total cholesterol, HDL-C, high-density lipoprotein - cholesterol, TG, triglyceride, OGTT, oral glucose tolerance test, HPLC, high-pressure liquid chromatography, LDL-C, lowdensity lipoprotein - cholesterol, SD, standard deviation, $\mathrm{CI}$, confidence interval, and CVD, cardiovascular disease.

\section{Acknowledgements}

We would like to thank the Deanship of Scientific Research at King Abdulaziz University, for funding this work under grant number (01-33-RG).

\section{Author Contributions}

All authors contributed to data analysis, drafting and revising the article, gave final approval of the version to be published, and agree to be accountable for all aspects of the work.

\section{Disclosure}

Jaakko Tuomilehto reports grants, non-financial support from Boehringer Ingelheim, during the conduct of the study; personal fees, non-financial support from Merck, grants, non-financial support from Boehringer Ingelheim, grants from Bayer, outside the submitted work. The authors declare there are no other conflicts of interest associated with this publication.

\section{References}

1. Barr EL, Zimmet PZ, Welborn TA, et al. Risk of cardiovascular and all-cause mortality in individuals with diabetes mellitus, impaired fasting glucose, and impaired glucose tolerance: the Australian Diabetes, Obesity, and Lifestyle Study (AusDiab). Circulation. 2007;116 (2):151-157. doi:10.1161/CIRCULATIONAHA.106.685628

2. Unwin N, Shaw J, Zimmet P, Alberti KG. Impaired glucose tolerance and impaired fasting glycaemia: the current status on definition and intervention. Diabet Med. 2002;19(9):708-723. doi:10.1046/j.14645491.2002.00835.x
3. Inoue K, Matsumoto M, Akimoto K. Fasting plasma glucose and HbA1c as risk factors for Type 2 diabetes. Diabetic Med. 2008;25 (10):1157-1163. doi:10.1111/dme.2008.25.issue-10

4. de Vegt F, Dekker JM, Jager A, et al. Relation of impaired fasting and postload glucose with incident type 2 diabetes in a Dutch population: the Hoorn Study. JAMA. 2001;285(16):2109-2113. doi:10.1001/ jama.285.16.2109

5. American Diabetes A. Diagnosis and classification of diabetes mellitus. Diabetes Care. 2012;35(Suppl 1):S64-71.

6. Cheng YJ, Gregg EW, Geiss LS, et al. Association of A1C and fasting plasma glucose levels with diabetic retinopathy prevalence in the U.S. population: implications for diabetes diagnostic thresholds. Diabetes Care. 2009;32(11):2027-2032. doi:10.2337/ dc09-0440

7. Ziegler D, Rathmann W, Dickhaus T, Meisinger C, Mielck A, Group KS. Prevalence of polyneuropathy in pre-diabetes and diabetes is associated with abdominal obesity and macroangiopathy: the MONICA/KORA Augsburg Surveys S2 and S3. Diabetes Care. 2008;31(3):464-469. doi:10.2337/dc07-1796

8. Diabetes Prevention Program Research G. The prevalence of retinopathy in impaired glucose tolerance and recent-onset diabetes in the Diabetes Prevention Program. Diabetic Med. 2007;24(2):137-144. doi:10.1111/dme.2007.24.issue-2

9. Plantinga LC, Crews DC, Coresh J, et al. Prevalence of chronic kidney disease in US adults with undiagnosed diabetes or prediabetes. Clin J Am Soc Nephrol. 2010;5(4):673-682. doi:10.2215/CJN.07891109

10. Abraham TM, Fox CS. Implications of rising prediabetes prevalence. Diabetes Care. 2013;36(8):2139-2141. doi:10.2337/dc13-0792

11. Hopper I, Billah B, Skiba M, Krum H. Prevention of diabetes and reduction in major cardiovascular events in studies of subjects with prediabetes: meta-analysis of randomised controlled clinical trials. Eur J Cardiovasc Prev Rehabil. 2011;18(6):813-823. doi:10.1177/ 1741826711421687

12. Tuomilehto J, Lindstrom J, Eriksson JG, et al. Prevention of type 2 diabetes mellitus by changes in lifestyle among subjects with impaired glucose tolerance. $N$ Engl $J$ Med. 2001;344(18):1343-1350. doi:10.1056/NEJM200105033441801

13. DeFronzo RA. Insulin resistance: a multifaceted syndrome responsible for NIDDM, obesity, hypertension, dyslipidaemia and atherosclerosis. Neth J Med. 1997;50(5):191-197. doi:10.1016/S0300-2977(97)00012-0

14. Bahijri SM, Jambi HA, Al Raddadi RM, Ferns G, Tuomilehto J. The prevalence of diabetes and prediabetes in the adult population of Jeddah, Saudi Arabia-A community-based survey. PLOS ONE. 2016;11(4):e0152559. doi:10.1371/journal.pone.0152559

15. Al Amiri E, Abdullatif M, Abdulle A, et al. The prevalence, risk factors, and screening measure for prediabetes and diabetes among Emirati overweight/obese children and adolescents. BMC Public Health. 2015;15:1298. doi:10.1186/s12889-015-2649-6

16. Murea M, Ma L, Freedman BI. Genetic and environmental factors associated with type 2 diabetes and diabetic vascular complications. Rev Diabetic Stud. 2012;9(1):6-22. doi:10.1900/RDS.2012.9.6

17. Stone NJ, Robinson JG, Lichtenstein AH, et al. 2013 ACC/AHA guideline on the treatment of blood cholesterol to reduce atherosclerotic cardiovascular risk in adults: a report of the American College of Cardiology/American Heart Association Task Force on practice guidelines. J Am Coll Cardiol. 2014;63(25Pt B):2889-2934. doi:10.1016/j.jacc.2013.11.002

18. Sedgwick P. Stratified cluster sampling. BMJ. 2013;347:f7016.

19. Bahijri SM, Al Raddadi RM. The importance of local criteria in the diagnosis of metabolic syndrome in Saudi Arabia. Ther Adv Endocrinol Metab. 2013;4(2):51-59. doi:10.1177/2042018813483165

20. Chobanian AV, Bakris GL, Black HR, et al. Seventh report of the Joint National Committee on Prevention, Detection, Evaluation, and Treatment of High Blood Pressure. Hypertension. 2003;42 (6):1206-1252. doi:10.1161/01.HYP.0000107251.49515.c2 
21. Phillips LS, Ziemer DC, Kolm P, et al. Glucose challenge test screening for prediabetes and undiagnosed diabetes. Diabetologia. 2009;52 (9):1798-1807. doi:10.1007/s00125-009-1407-7

22. Castro A, Scott JP, Grettie DP, Macfarlane D, Bailey RE. Plasma insulin and glucose responses of healthy subjects to varying glucose loads during three-hour oral glucose tolerance tests. Diabetes. 1970;19(11):842-851. doi:10.2337/diab.19.11.842

23. Friedewald WT, Levy RI, Fredrickson DS. Estimation of the concentration of low-density lipoprotein cholesterol in plasma, without use of the preparative ultracentrifuge. Clin Chem. 1972;18(6):499-502.

24. American Diabetes A. Diagnosis and classification of diabetes mellitus. Diabetes Care. 2014;37(Suppl 1):S81-90.

25. Bansal N. Prediabetes diagnosis and treatment: a review. World $J$ Diabetes. 2015;6(2):296-303. doi:10.4239/wjd.v6.i2.296

26. Alberti KG, Eckel RH, Grundy SM, et al. Harmonizing the metabolic syndrome: a joint interim statement of the International Diabetes Federation Task Force on Epidemiology and Prevention; National Heart, Lung, and Blood Institute; American Heart Association; World Heart Federation; International Atherosclerosis Society; and International Association for the Study of Obesity. Circulation. 2009;120 (16):1640-1645. doi:10.1161/CIRCULATIONAHA.109.192644

27. Third Report of the National Cholesterol Education Program (NCEP). Expert panel on detection, evaluation, and treatment of high blood cholesterol in adults (Adult Treatment Panel III) final report. Circulation. 2002;106(25):3143-3421. doi:10.1161/circ.106.25.3143

28. Al-Rubeaan K, Al-Manaa H, Khoja T, et al. The Saudi Abnormal Glucose Metabolism and Diabetes Impact Study (SAUDI-DM). Ann Saudi Med. 2014;34(6):465-475. doi:10.5144/0256-4947.2014.465

29. Harris MI, Flegal KM, Cowie CC, et al. Prevalence of diabetes, impaired fasting glucose, and impaired glucose tolerance in U.S. adults. The Third National Health and Nutrition Examination Survey, 1988-1994. Diabetes Care. 1998;21(4):518-524. doi:10.2337/ diacare.21.4.518

30. Ramachandran A. Epidemiology of type 2 diabetes in Indians. J Indian Med Assoc. 2002;100(7):425-427.

31. Thabit H, Burns N, Shah S, et al. Prevalence and predictors of diabetes and cardiometabolic risk among construction workers in Ireland: the Construction Workers Health Trust screening study. Diabetes Vasc Dis Res. 2013;10(4):337-345. doi:10.1177/1479164113479808

32. Definition and diagnosis of diabetes mellitus and intermediate hyperglycemia. World Health Organization and International Diabetes Federation Consultation Report. Geneva; 2006.

33. Dagogo-Jack S, Edeoga C, Ebenibo S, Nyenwe E, Wan J. Lack of racial disparity in incident prediabetes and glycemic progression among black and white offspring of parents with type 2 diabetes: the pathobiology of prediabetes in a biracial cohort (POP-ABC) study. J Clin Endocrinol Metab. 2014;99(6):E1078-1087. doi:10. 1210/jc.2014-1077
34. Kansal S, Kamble TK. Lipid profile in prediabetes. $J$ Assoc Physicians India. 2016;64(3):18-21.

35. Nam GE, Han K, Kim DH, et al. Relationship between dyslipidemia and albuminuria in prediabetic adults: the Korea National Health and Nutrition Examination Survey 2011-2012. Endocrine. 2015;48 (2):557-565. doi:10.1007/s12020-014-0411-y

36. Vandama Balgi LH, Sahna E, Thomas SK. Pattern of lipid profile abnormality in subjects with prediabetes. Int J Sci Study. 2017;4:11.

37. Owei I, Umekwe N, Wan J, Dagogo-Jack S. Plasma lipid levels predict dysglycemia in a biracial cohort of nondiabetic subjects: potential mechanisms. Exp Biol Med. 2016;241(17):1961-1967. doi: $10.1177 / 1535370216659946$

38. Zheng S, Xu H, Zhou H, et al. Associations of lipid profiles with insulin resistance and beta cell function in adults with normal glucose tolerance and different categories of impaired glucose regulation. PLoS ONE. 2017;12(2):e0172221. doi:10.1371/journal.pone.0172221

39. Chakarova N, Tankova T, Atanassova I, Dakovska L. Serum lipid and hsCRP levels in prediabetes-impaired fasting glucose (IFG) and impaired glucose tolerance (IGT). Diabetes Res Clin Pract. 2009;86 (1):56-60. doi:10.1016/j.diabres.2009.04.005

40. Chang YC, Wu WC. Dyslipidemia and diabetic retinopathy. Rev Diabetic Stud. 2013;10(2-3):121-132. doi:10.1900/RDS.2013.10.121

41. Fonseca VA. Defining and characterizing the progression of type 2 diabetes. Diabetes Care. 2009;32(Suppl 2):S151-156. doi:10.2337/ dc09-S301

42. Tabak AG, Herder C, Rathmann W, Brunner EJ, Kivimaki M. Prediabetes: a high-risk state for diabetes development. Lancet. 2012;379(9833):2279-2290. doi:10.1016/S0140-6736(12)60283-9

43. Ryden L, Grant PJ, Anker SD, et al. ESC guidelines on diabetes, pre-diabetes, and cardiovascular diseases developed in collaboration with the EASD: the Task Force on diabetes, pre-diabetes, and cardiovascular diseases of the European Society of Cardiology (ESC) and developed in collaboration with the European Association for the Study of Diabetes (EASD). Eur Heart J. 2013;34(39):3035-3087. doi:10.1093/eurheartj/eht108

44. Khavandi K, Amer H, Ibrahim B, Brownrigg J. Strategies for preventing type 2 diabetes: an update for clinicians. Ther Adv Chronic Dis. 2013;4(5):242-261. doi:10.1177/2040622313494986

\section{Publish your work in this journal}

Diabetes, Metabolic Syndrome and Obesity: Targets and Therapy is an international, peer-reviewed open-access journal committed to the rapid publication of the latest laboratory and clinical findings in the fields of diabetes, metabolic syndrome and obesity research. Original research, review, case reports, hypothesis formation, expert opinion and commentaries are all considered for publication. The manuscript management system is completely online and includes a very quick and fair peer-review system, which is all easy to use. Visit http://www.dovepress.com/testimonials.php to read real quotes from published authors. 